\title{
A comparative study of Doppler ultrasound against temporal artery biopsy in the diagnosis of giant cell arteritis
}

\author{
Estudio comparativo de la ecografía Doppler frente a la biopsia de arteria temporal en \\ el diagnóstico de la arteritis de células gigantes
}
Sara Alicia González Porto ${ }^{\mathrm{a}}$, María Teresa Silva Díaz ${ }^{\mathrm{b}}$, Ana Reguera Arias ${ }^{\mathrm{c}}$, Jorge Pombo Otero ${ }^{c}$, Alba González Rodríguez ${ }^{\mathrm{d}}$, Javier Valero Gasalla ${ }^{\mathrm{d}}$, Francisco Javier deToro Santos ${ }^{\mathrm{b}}$

\author{
${ }^{a}$ Servicio de Cirugía Plástica, Hospital POVISA, Vigo, Spain \\ ${ }^{b}$ Servicio de Reumatología, Complexo Hospitalario Universitario de A Coruña, La Coruña, Spain \\ c Servicio de Anatomía Patológica, Complexo Hospitalario Universitario de A Coruña, La Coruña, Spain \\ ${ }^{d}$ Servicio de Cirugía Plástica, Complexo Hospitalario Universitario de A Coruña, La Coruña, Spain
}

Corresponding author.

E-mail addresses: sagonzalez@povisa.es, sarali.gonzalezporto@gmail.com (S.A. González Porto).

\begin{abstract}
Background.Giant cell arteritis (GCA) is a vasculitis that affects medium- and large-sized arteries. Temporal artery biopsy is the gold standard for diagnosis. In view of the high demand for temporal biopsies, the purpose of this study is to evaluate the usefulness of Doppler ultrasonography in patients with suspected giant cell arteritis, to determine its sensitivity and specificity as a diagnostic test and to determine whether it would be possible to substitute biopsy for ultrasonography.

Materials and methods. A prospective study was undertaken including 57 patients from February 2015 to July 2016, who have undergone both ultrasonography and temporal biopsy.

Results. A total of 57 patients were included, 3 of whom died during the follow-up, and a patient was excluded from the study when she refused to have the biopsy. Another 21 patients were diagnosed with GCA by a rheumatologist after a minimum of 6 months of follow-up and 22 patients had positive ultrasonography, 8 of whom were diagnosed with GCA and 4 with polymyalgia rheumatica. In our study, the sensitivity of ultrasonography was $42.6 \%$, and the specificity was $65.7 \%$. A total of 19 patients had a positive biopsy, all of them were diagnosed with GCA. In our study, the sensitivity of the biopsy was $73.7 \%$ and the specificity was $100 \%$.

Conclusions. In view of the data from our study, the usefulness of ultrasonography is questionable, and research about the role of ultrasonography in this disease should be further studied.
\end{abstract}




\section{Resumen}

Introducción. La arteritis de células gigantes (ACG) es una vasculitis que afecta a arterias de mediano y gran calibre. La biopsia de la arteria temporal es la técnica diagnóstica de elección. Atendiendo a la demanda asistencial que supone, pretendemos evaluar la utilidad de la ecografía Doppler en los pacientes con sospecha de ACG, su sensibilidad y especificidad como prueba diagnóstica y si puede suplir a la biopsia.

Materiales y métodos. Se ha realizado un estudio prospectivo de 57 pacientes entre febrero de $2015 \mathrm{y}$ julio de 2016, que han sido diagnosticados con exploración mediante ecografía Doppler y biopsia de arteria temporal.

Resultados. Fueron incluidos 57 pacientes, de los cuales 3 fallecieron durante el seguimiento y una paciente fue excluida del estudio al negarse a la biopsia. Otros 21 pacientes fueron diagnosticados de ACG por un especialista reumatólogo tras un mínimo de 6 meses de seguimiento. Presentaron ecografía positiva 22 pacientes, de los cuales 8 fueron diagnosticados de ACG y 4 de polimialgia reumática. En nuestro estudio, la sensibilidad de la ecografía es del $42.6 \%$ y la especificidad es del $65.7 \%$. Otros 19 pacientes presentaron biopsia positiva: todos ellos fueron diagnosticados de ACG. La biopsia presentóuna sensibilidad de un $73.7 \%$ y una especificidad de un $100 \%$.

Conclusiones. Según nuestro estudio, la utilidad de la ecografía es limitada y son necesarias nuevas investigaciones para determinar su papel en esta entidad.

\section{Keywords}

Temporal artery; Giant cell arteritis; Temporal artery arteritis; Horton disease; Doppler ultrasonography; Biopsy

\section{Palabras clave}

Arteria temporal; Arteritis de células gigantes; Arteritis de la arteria temporal; Enfermedad de Horton; Ecografía Doppler; Biopsia 


\section{Introduction}

Giant cell arteritis (GCA) or Horton's arteritis is a vasculitis that affects the medium and large arteries $^{1}$ the temporal artery being the most frequently affected. It almost exclusively affects people over 50 years of age and the annual frequency in this sector of the population varies from 6.9 to 32.8 per 100,000 inhabitants according to the population affected. ${ }^{2}$ Despite being a relatively rare disease, the estimated annual incidence in Spain is around 11 new cases per 100,000 inhabitants in people over 50 years of age. ${ }^{3}$

To date, studies point to causes of immunological origin. CD4+ T-lymphocytes are mainly responsible for triggering the factors that lead to vascular damage.

The main associated complication is ischaemic optic neuritis with subsequent blindness, which, although it may at the onset of the disease, is usually prevented by empirical steroid treatment when the disease is suspected. ${ }^{4}$

Currently, the diagnosis of choice is made by pathological anatomy, which reveals polyarteritis with inflammatory mononuclear infiltrates in the vascular wall and frequent giant cells, and whose main limitation is low sensitivity. This low sensitivity is due, firstly, to the patchy involvement of the vessels, which is why the minimum required length of the biopsied vessel is between 1.5 and $2 \mathrm{~cm}$ and, secondly, to false negatives caused by early treatment with glucocorticoids. The current diagnostic criteria state that patients with positive biopsy should always be treated; the clinical problem is posed by patients with a negative biopsy result. If the pre-test likelihood is high, these patients should also be treated, although the frequency of severe ischaemic events (including blindness) is lower in this group..$^{5,6}$

We now know that potential loss of vision makes early treatment of the disease critical. Despite the fact that treatment with steroids increases the rate of false negatives in the biopsy, there is an international agreement that it is unacceptable to assume the risk of blindness postponing starting therapy in order to avoid negative pathological anatomy. 
That is why biopsy should be performed as soon as possible, in the knowledge that the possibility of false negatives dramatically increases after 16 days. $^{7}$

Temporal artery biopsy is a procedure that is usually performed on an outpatient basis and ranges from 20 to $50 \mathrm{~min}$ in surgical time. It presents a complication rate of between $.5 \%$ and $1 \%$, the main complication being bleeding (haemorrhage or haematoma), followed by surgical wound infection, nerve injury, vascular injury (arterial or venous), skin necrosis or stroke.

Doppler ultrasound has been proposed as an alternative to biopsy in the diagnosis of arteritis, although the results of the studies available in the literature are contradictory. The appearance of a halo around the arterial lumen is considered for ultrasound diagnosis, as well as stenosis and occlusion. This hypoechoic halo on the arterial wall is probably caused by oedema, which usually disappears at 2 weeks after starting treatment with steroids. ${ }^{8}$ The presence of stenosis or vascular occlusion has also been described.

There are several studies that recommend biopsy for all patients, regardless of the presence of the halo sign, and to reserve ultrasound for those cases with high suspicion and contraindications for surgery. ${ }^{9}$ However, there are meta-analyses that recommend ultrasound as an initial diagnostic test, with halo sign sensitivity of $75 \%$ and specificity of $83 \%$, and propose reserving biopsy for cases with negative ultrasound. ${ }^{10}$ Some authors propose substituting biopsy with Doppler ultrasound of the temporal, axillary and common carotid arteries, claiming sensitivities of $100 \%$ and specificities of $96 \%$ with ultrasound. ${ }^{11}$ In some clinical studies it has been considered "equivalent to biopsy", and is proposed as an alternative because it is an efficient and safe test for the patient. Given this debate in the literature, our aim was to collaborate in contributing to the knowledge on the role of ultrasound in the diagnosis of temporal arteritis. We aimed to determine the sensitivity and specificity of ultrasound (safe and rapid test) with respect to biopsy (invasive and slow test), its diagnostic indications and the situations that it could be a substitute for biopsy, to optimise operating theatre occupation and reduce healthcare costs. 


\section{Materials and methods}

A comparative and prospective study was conducted to analyse the sensitivity and specificity of Doppler ultrasound as a diagnostic test in the context of suspected GCA versus temporal artery biopsy, the current gold standard diagnostic method.

The main objective of our study was to evaluate the diagnostic validity of temporal artery colour Doppler ultrasound in GCA, in terms of sensitivity and specificity compared to temporal artery biopsy. As a secondary objective, we analysed the patient sample according to the American College of Rheumatology (ACR) criteria for temporal arteritis. ${ }^{12}$

To conduct this study, we obtained the approval of the Ethics Committee and the informed consent of the patients included.

\section{Population included in the study}

A total of 57 patients were included in the study population. All patients suspected of having temporal arteritis according to a rheumatologist, neurologist or internal practitioner were included in chronological order of arrival, either due to clinical suspicion (headache, mandibular claudication, asthenia, scapular or pelvic girdle pain...) or due to analytical suspicion (anaemia, elevated ESR...), for whom the specialist decided a diagnostic temporal artery biopsy, in the absence of contraindications for the procedure.

\section{Description of the study phases and variables analysed}

At the first visit, the demographic data, personal history, clinical manifestations reported by the patient, as well as the findings on physical examination were recorded. Poor general condition was differentiated from the general syndrome, and therefore the latter included patients who presented, in addition to asthenia, anorexia and weight loss. The comorbidity of the patients was evaluated by Charlson score, which considers patients' mortality risk per year according to the number and 
characteristics of systemic diseases present (heart, vascular, brain, lung, liver, gastric, renal, haematological, connective tissue diseases, presence of diabetes, tumour or AIDS).

In addition, relevant analytical data were collected in relation to the disease under study and history of recent steroid treatment.

At the second visit, diagnostic tests were performed for comparison. Firstly, colour Doppler ultrasound was performed on both temporal arteries using a Mindray Z6 ultrasound machine with a 7L4P linear probe. The ultrasound parameters or settings used to evaluate the patients were a frequency of 10 and gain of 39. For the colour settings, the frequency was 5.7, the gain was 32 and the PRF (pulse repetition frequency) was 1.1. All ultrasound examinations were performed by the same rheumatologist, trained in Doppler ultrasound. The duration of the examination was between 20 and $30 \mathrm{~min}$. However, the rheumatologist who performed the ultrasound was not blind to the patients' clinical and analytical findings.

Secondly, less than $36 \mathrm{~h}$ after the ultrasound scan, the temporal artery biopsy was performed. The size of the temporal artery biopsy was at least $1 \mathrm{~cm}$ and right or left laterality was determined according to the side with the predominant symptoms. ${ }^{13}$ The biopsy was performed blind, i.e., the surgeon did not know the results of the patient's ultrasound.

The data collected during ultrasound were the duration of the procedure in minutes, the presence or absence of halo sign, stenosis or occlusion of the artery and whether these signs were unilateral or bilateral. The ultrasound scan was considered positive if any of the above signs appeared unilaterally or bilaterally.

As for the biopsy, the duration of the procedure and the existence and type of intraoperative complications were recorded. 
In the postoperative visits, the result of the anatomopathological analysis of the surgical specimen was recorded (positive if it was compatible with GCA, negative if it was not, and indeterminate if the findings were not sufficient for diagnosis of GCA), and the existence and type of postoperative complications (bleeding, haematoma, infection, nerve damage, surgical wound dehiscence or skin necrosis).

\section{Statistical analysis}

The sensitivity and specificity of the bilateral temporal artery Doppler ultrasound were calculated, as well as the sensitivity and specificity of the temporal artery biopsy.

A descriptive study of all the variables included in the study was performed, expressing the qualitative variables as absolute values and percentages; the quantitative variables as mean \pm standard deviation, together with their $95 \%$ confidence interval.

The Chi-square test or Fisher's exact test was used to compare proportions. Comparison of means was performed, after checking the normality with the Kolmogorov-Smirnov test, with the Student's $t$-test or the Mann-Whitney U test.

Correlations between quantitative measurements were determined by means of Spearman's rho correlation coefficient.

The validity of Doppler ultrasound with respect to biopsy (gold standard) was studied by means of an analysis of sensitivity, specificity and positive and negative predictive values, together with their $95 \%$ confidence intervals. The validity of Doppler ultrasound in relation to GCA criteria was also studied.

The analyses were performed using the Statistical Package for the Social Sciences software, version 19.0 (SPSS, Chicago, IL, USA). 


\section{Results}

A total of 57 patients were included in the study, of whom 3 died during follow-up and one patient was excluded from the study after refusing the biopsy after their inclusion in the protocol.

The average time for the temporal artery ultrasound was $14.4 \mathrm{~min}$, and the average time for the biopsy was $26.2 \mathrm{~min}$.

With regard to onset of complications, none associated with the ultrasound, nor any intraoperative complication during the biopsy were evident. However, after the biopsy was performed, postoperative complications occurred in 3 patients, all of them mild. The complications described were bleeding, local haematoma-which did not require surgical drainage-and formation of an epidermal cyst in the scar.

The clinical and analytical data suspicious of GCA are specified in Table 1. Qualitative variables are presented in number of cases (percentage of the total number of patients). The qualitative variables are presented in number of cases (percentage of the total number of patients). The suspicion of GCA derived in most cases from elevated ESR, the presence of normocytic anaemia or headache.

The most frequent manifestations were, in the analytical data, elevated ESR- in $85.9 \%$ of the cases-the presence of normocytic normochromic anaemia-present in $67.3 \%$ of the patients- and symptoms of headache, poor general condition, visual symptoms and pain in the pelvic or scapular girdle, which were present in $61.4 \%, 45.6 \%, 36.8 \%$ and $36.8 \%$ of the patients, respectively. Less frequently, mandibular claudication appeared in $24.6 \%$, general syndrome in $21.1 \%$, stroke in $10.5 \%$, fever in $7 \%$ and infarction in $3.5 \%$ of patients. Table 2 shows the demographics, personal history, clinical data and ultrasound results and the percentage to which they relate to the diagnosis of GCA. Normocytic normochromic anaemia is the disorder most frequently associated with a diagnosis of GCA, but without statistically significant value. Of all the clinical histories, significant differences were only found between the groups in Charlson score, 
significantly higher in the patients not diagnosed with GCA, and in mandibular claudication, significantly more present in the patients diagnosed with GCA.

Regarding the specialty that indicated biopsy, internal medicine indicated the most biopsies, with 35 patients referred $(61.4 \%)$ and 8 positive results in the biopsy with respect to the total number of biopsies sent (22.8\%) (Table 3). Rheumatology was the department with the highest percentage of positive biopsies in relation to those indicated, which referred 18 patients $(31.6 \%)$, with 10 positive biopsies $(55.5 \%)$. The neurology department referred 3 patients $(5.3 \%)$ with a positive result $(33.3 \%)$ and the primary care service referred 1 patient $(1.7 \%)$ without obtaining a positive result.

Of the 57 patients included who underwent ultrasound and biopsy, only 21 were diagnosed with GCA by a rheumatology specialist after a minimum of 6 months of follow-up. Of the 22 patients who tested positive in the ultrasound study, only 8 were diagnosed with GCA and 4 were diagnosed with polymyalgia rheumatica. Of the 19 patients who presented a positive biopsy, all were diagnosed with GCA.

Of the 57 patients, 37 met at least 3 of the 5 GCA criteria (all over 50 years old, 35 headache, 30 sensitivity to temporal artery palpation or decreased pulse, 44 ESR $\geq 50$ and 19 positive biopsies). When comparing these criteria with ultrasound, its sensitivity was $77.3 \%$ (95\% CI: $56.6 \%-89.9 \%$ ) and specificity $41.2 \%$ (95\% CI: $26.4 \%-57.8 \%$ ). When comparing the GCA criteria with biopsy, the sensitivity of biopsy was $92.9 \%$ (95\% CI: $68.5 \%-98.7 \%$ ) and the specificity was $42.9 \%$ (95\% CI: $29.1 \%-57.8 \%$ ).

Comparing the ultrasound and biopsy with the final diagnosis given by a rheumatologist, the sensitivity of ultrasound was $42.6 \%$ and specificity $65.7 \%$, assessing the test as positive with the presence of halo sign, or stenosis or occlusion of at least one of the temporal arteries (Table 4). If we evaluate each of the ultrasound signs independently, we obtain a sensitivity of $33.3 \%, 14.2 \%$ and $9.5 \%$, respectively, for each and a specificity of $68.5 ; 94.2$ and $97.1 \%$. The sensitivity of ultrasound is higher, considering a positive ultrasound as the presence of halo sign, or stenosis or occlusion; however, the specificity of the test is low: it does not reach 70\%. Likewise, 
the sensitivity obtained for biopsy was $73.7 \%$ and the specificity $100 \%$. In the follow up, it was observed that treatment with steroids in the patients diagnosed with GCA was significantly higher than in the group of undiagnosed patients, although no significant differences between doses were evidenced. However, steroid therapy was maintained in almost half of the undiagnosed patients with GCA at 3 months following the ultrasound/biopsy.

\section{Discussion}

The prospective study included 57 patients with suspected temporal arteritis who underwent Doppler ultrasound of both temporal arteries and temporal artery biopsy. With respect to the GCA criteria, the sensitivity and specificity of ultrasound were $77.3 \%$ and $41.2 \%$, respectively, and the sensitivity and specificity of biopsy were $92.9 \%$ and $42.9 \%$.

Regarding the clinical and analytical findings of the patients included in the study, high ESR was the most frequently found, followed by anaemia and headache.

Peral-Cagigal et al. found significant differences between the group of patients with GCA and the control group in the presence of temporal headache and mandibular claudication. ${ }^{14}$ However, in our study, the difference between the group of patients diagnosed with arteritis and the group without this diagnosis was only significant in the case of mandibular claudication.

In relation to the specialty indicating performing biopsy, the percentage of positive biopsies was much higher in the group of biopsies indicated by the rheumatology specialists $(55.5 \%)$.

We know that although diagnosis of GCA is based on clinical history, physical examination, complementary imaging and laboratory tests, confirmation is histological through temporal artery biopsy. ${ }^{15,16,17}$ In 1997 Schmidt recognised the role of colour duplex ultrasound in diagnosis. ${ }^{8}$ According to their study, the halo sign had sensitivity 
with respect to biopsy of $76 \%$ and specificity of $92 \%$. When the halo sign, stenosis and occlusion, were considered sensitivity increased to $95 \%$ and specificity decreased to $85 \%$. Schmidt's group considered ultrasound to be especially useful in those patients with high clinical suspicion of GCA, and therefore they started treatment with steroids in the patients with ultrasound signs typical of temporal arteritis without performing a biopsy of the temporal artery, unless another arteritis was suspected, and proposed reserving biopsy for patients with high clinical suspicion with negative ultrasound.

In the following years, multiple studies were performed comparing ultrasound with biopsy or with GCA criteria, among which 2 meta-analyses stand out. ${ }^{18,19,20,21,22}$

In the first of these, by Karassa et al., 23 studies (2036 patients) were analysed, with a sensitivity of $55 \%(36 \%-73 \%)$ with respect to meeting GCA criteria, and 69\% (57\%$79 \%$ ) with respect to biopsy. ${ }^{23}$ Specificity was $94 \%(82 \%-98 \%)$ and $82 \%(75 \%-87 \%)$, respectively. From this meta-analytic study, it is necessary to highlight the wide confidence interval of ultrasound sensitivity with respect to GCA criteria, since in some of the studies included in the analysis the sensitivity of ultrasound was less than $50 \%$. As a conclusion of the article cited, the usefulness of ultrasound is deduced as limited, since if the pre-test likelihood of GCA is low, a negative ultrasound does not exclude the need for biopsy, while a positive ultrasound is inconclusive. If the pre-test likelihood is high, biopsy is recommended to confirm the diagnosis.

The second meta-analysis is that of Arida et al. in which they included 8 prospective studies (575 patients) that compared the sensitivity and specificity of ultrasound with GCA criteria. ${ }^{24}$ Considering a unilateral halo on the ultrasound as diagnostic of GCA, sensitivity according to this meta-analysis is $68 \%(61 \%-64 \%)$ and specificity $91 \%$ (88\%-94\%). Considering a bilateral halo sign, sensitivity decreases to $43 \%$ and specificity increases to $100 \%$. The authors conclude that treatment could be initiated or continued if a bilateral halo sign is observed, without the need for biopsy. However, if the halo is only unilateral, they propose performing a biopsy. 
The systematic review by Ball et al. includes 17 studies (998 patients) in which the sensitivity and specificity of the ultrasound findings are compared with biopsy or GCA criteria. $^{12}$ The sensitivity of the halo sign with respect to biopsy is $75 \%(67 \%-82 \%)$ and specificity is $83 \%(78 \%-88 \%)$. If the halo sign or stenosis or occlusion is compared with biopsy, the sensitivity increases to $83 \%(77 \%-89 \%)$ and specificity decreases to $82 \%(77 \%-87 \%)$. When comparing halo sign with GCA criteria, sensitivity is $69 \%$ $(60 \%-77 \%)$ and specificity $89 \%(84 \%-92 \%)$. When comparing the characteristic 3 findings of ultrasound with the GCA criteria, the sensitivity is $78 \%(72 \%-84 \%)$ and specificity is $88 \%(84 \%-91 \%)$.

More recently, Monti et al. studied the role of ultrasound in the management of GCA in routine clinical practice in their study of 293 patients. ${ }^{25}$ Sensitivity of ultrasound is $63.3 \%$ and specificity is $100 \%$ compared to the clinical diagnosis of GCA, in patients treated with steroids for less than one week. In their study they concluded that ultrasound has a high positive predictive value in the diagnosis of GCA and that it enables the number of biopsies of the temporal artery to be reduced. This conclusion was possible due to the high specificity obtained, which is higher than that of other publications, in which specificity is around $80 \%-90 \%$. In our study, we obtained a sensitivity of $42.6 \%$ and specificity of $65.7 \%$ with respect to diagnosis of GCA by a rheumatologist. If we compare ultrasound with respect to GCA criteria, sensitivity increases to $77.3 \%$, but specificity decreases to $41.2 \%$. This low specificity encountered implies a low positive predictive value of Doppler ultrasound in GCA and, therefore, we consider that performing a biopsy in patients with positive Doppler ultrasound cannot be avoided.

The low sensitivity found in our study can be explained if we take into account the exclusive evaluation of the temporal artery as opposed to evaluation of other arteries in addition to the temporal artery in other studies, as is the case with the carotid artery, or the facial or occipital artery, which could increase the sensitivity of the ultrasound technique. ${ }^{26}$ Ješe et al. propose studying the facial and occipital artery, in addition to the temporal artery, since $18 \%$ of the patients included show halo sign in the occipital or 
facial artery, with no ultrasound abnormalities in the temporal artery, and they assume an increase in the diagnosis of GCA of $4.3 \%$.

However, the sensitivity of ultrasound in our study with respect to GCA criteria is similar to that found in the literature, which as we have already mentioned is highly variable, varying from $36 \%$ to $89 \%$ between the different studies.

The specificity of ultrasound in our study with respect to GCA criteria is lower than that found in the literature, with the same limitation, already mentioned, for sensitivity, which is the variability that stands out among the studies.

Other factors, such as time of steroid therapy prior to ultrasound or biopsy, or the operator-dependence of ultrasound, could also contribute to these differences in sensitivity and specificity. There are other groups who, like ours, consider that only in the case of highly experienced sonographers can ultrasound be a substitute for biopsy. ${ }^{27}$ However, Nesher et al. present sensitivity and specificity of the halo sign of $86 \%$ and $78 \%$, respectively, and associate the absence of halo sign in the temporal arteries with a high negative predictive value of GCA, such that they do not perform temporal artery biopsy in patients with a negative ultrasound. ${ }^{28} \mathrm{We}$ consider that, due to the low sensitivity of ultrasound with respect to GCA criteria, we should also perform biopsy in patients with negative ultrasound. Similarly, as the observed specificity of ultrasound with respect to GCA criteria is also low, we believe that biopsy should be performed in patients with positive ultrasound. The same opinion is held by the group of Maldini et al., whose study with 77 patients found a specificity of $100 \%$ of the halo sign in the diagnosis of GCA with sensitivity of only $10 \%-17 \%$. Therefore, they conclude that ultrasound is neither an effective substitute for biopsy nor safe for deciding the patients that do not require biopsy. ${ }^{29}$

Regarding the steroid treatment of the patients included in the study, although we found no significant difference between the groups before biopsy, steroid therapy was significantly higher in the patients diagnosed with temporal artery arteritis than in those not diagnosed with arteritis after the biopsy. The performance of biopsy helps diagnosis 
in the case of a positive result, and the negative result in our study is associated with a significant reduction in the percentage of patients treated with steroids.

In our study, the comparison of ultrasound with the opinion of a rheumatologist, which we consider the gold standard in this paper, is a methodological limitation that needs to be highlighted. However, we also analysed the sensitivity and specificity of biopsy and ultrasound using GCA criteria as the benchmark standard, to facilitate the extrapolation of our results to other studies in the literature. It is necessary to highlight the different clinical expression of GCA in patients whose diagnosis has been confirmed by biopsy, in whom the risk of ischaemic events is much higher, and those diagnosed using the GCA classification criteria. ${ }^{6}$ Therefore, the sensitivity and specificity of ultrasound could possibly be improved if our study were to compare ultrasound findings with biopsy, considering those patients diagnosed by positive biopsy.

Another limitation is that the rheumatologist who performed the ultrasound was not blinded to the clinical and analytical findings of the patients. However, no significant differences in examination time were found between the patients.

Considering the findings of this study, we believe that clinical and patient assessment by a rheumatology specialist remains the basis for optimising the indication for temporal artery biopsy. In our opinion, and according to the results obtained, ultrasound has its indication in patients with a high likelihood of presenting the disease, but in whom surgery is not recommended. However, biopsy continues to be the diagnostic test indicated in our routine clinical practice.

\section{Conflict of interests}

The authors have no conflict of interests to declare. 


\section{References}

1. Salvarani C, Cantini F, Hunder GG. Polymyalgia rheumatica and giant-cell arteritis. Lancet. 2008;372:234-45.

2. Gonzalez-Gay MA, Vazquez-Rodriguez TR, Lopez-Diaz MJ, Miranda-Filloy JA, GonzalezJuanatey C, Martin J, et al. Epidemiology of giant cell arteritis and polymyalgia rheumatica. Arthritis Rheum. 2009;61:1454-61.

3. Gonzalez-Gay MA, Miranda-Filloy JA, Lopez-Diaz MJ, Perez-Alvarez R, Gonzalez Juanatey C, Sanchez-Andrade A, et al. Giant cell arteritis in northwestern Spain: a 25-year epidemiologic study. Medicine (Baltimore). 2007;86:61-8.

4. Gonzalez-Gay MA, Castañeda S, Llorca J. Giant cell arteritis: visual loss is our major concern. J Rheumatol. 2016;43:1458-61.

5. Murchison AP, Gilbert ME, Bilyk JR, Eagle RC, Pueyo V, Sergott RC, et al. Validity of the American College of Rheumatology criteria for the diagnosis of giant cell arteritis. Am $\mathrm{J}$ Ophthalmol. 2012;154:722-9.

6. Gonzalez-Gay MA, Garcia-Porrua C, Llorca J, Gonzalez-Louzao C, Rodriguez-Ledo P. Biopsynegative giant cell arteritis: clinical spectrum and predictive factors for positive temporal artery biopsy. Semin Arthritis Rheum. 2001;30:249-56.

7. Black R, Roach D, Rischmueller M, Lester SL, Hill CL. The use of temporal artery ultrasound in the diagnosis of giant cell arteritis in routine practice. Int J Rheum Dis. 2013;16:352-7.

8. Schmidt WA, Kraft HE, Vorpahl K, Völker L, Gromnica-Ihle EJ. Color duplex ultrasonography in the diagnosis of temporal arteritis. N Engl J Med. 1997;337:1336-42.

9. Muratore F, Boiardi L, Restuccia G, Macchioni P, Pazzola G, Nicolini A, et al. Comparison between colour duplex sonography findings and different histological patterns of temporal artery. Rheumatol Oxf Engl. 2013;52:2268-74.

10. Karahaliou M, Vaiopoulos G, Papaspyrou S, Kanakis MA, Revenas K, Sfikakis PP. Colour duplex sonography of temporal arteries before decision for biopsy: a prospective study in 55 patients with suspected giant cell arteritis. Arthritis Res Ther. 2006;8:116.

11. Diamantopoulos AP, Haugeberg G, Hetland H, Soldal DM, Bie R, Myklebust G. Diagnostic value of color Doppler ultrasonography of temporal arteries and large vessels in giant cell arteritis: a consecutive case series. Arthritis Care Res. 2014;66:113-9.

12. Ball EL, Walsh SR, Tang TY, Gohil R, Clarke JM. Role of ultrasonography in the diagnosis of temporal arteritis. Br J Surg. 2010;97:1765-71.

13. Gonzalez-Gay MA. The diagnosis and management of patients with giant cell arteritis. J Rheumatol. 2005;32:1186-8.

14. Peral-Cagigal B, Perez-Villar Á, Redondo-Gonzalez L-M, Garcia-Sierra C, Morante-Silva M, Madrigal-Rubiales B, et al. Temporal headache and jaw claudication may be the key for the diagnosis of giant cell arteritis. Med Oral Patol Oral Cirugia Bucal. 2018;23:290-4. 
15. Weyand CM, Goronzy JJ. Clinical practice. Giant-cell arteritis and polymyalgia rheumatica. N Engl J Med. 2014;371:50-7.

16. Jodo S, Hisada R. Giant cell arteritis. Nihon Rinsho Meneki Gakkai Kaishi. 2013;36:459-66.

17. Ciccia F, Ferrante A, Guggino G, Cavazza A, Salvarani C, Rizzo A. CD3 immunohistochemistry is helpful in the diagnosis of giant cell arteritis. Rheumatol Oxf Engl. 2018.

18. Luqmani R, Lee E, Singh S, Gillett M, Schmidt WA, Bradburn M, et al. The role of ultrasound compared to biopsy of temporal arteries in the diagnosis and treatment of giant cell arteritis (TABUL): a diagnostic accuracy and cost-effectiveness study. Health Technol Assess Winch Engl. 2016;20:1-238.

19. Croft AP, Thompson N, Duddy MJ, Barton C, Khattak F, Mollan SP, et al. Cranial ultrasound for the diagnosis of giant cell arteritis. A retrospective cohort study. J R Coll Physicians Edinb. 2015;45:268-72

20. Monti S, Floris A, Ponte C, Schmidt WA, Diamantopoulos AP, Pereira C, et al. The use of ultrasound to assess giant cell arteritis: review of the current evidence and practical guide for the rheumatologist. Rheumatol Oxf Engl. 2018;57:227-35.

21. Germanò G, Monti S, Ponte C, Possemato N, Caporali R, Salvarani C, et al. The role of ultrasound in the diagnosis and follow-up of large-vessel vasculitis: an update. Clin Exp Rheumatol. 2017;35 Suppl 103(1):194-8.

22. Roncato C, Allix-Béguec C, Brottier-Mancini E, Gombert B, Denis G. Diagnostic performance of colour duplex ultrasonography along with temporal artery biopsy in suspicion of giant cell arteritis. Clin Exp Rheumatol. 2017;35 Suppl 103(1):119-22.

23. Karassa FB, Matsagas MI, Schmidt WA, Ioannidis JP. Meta-analysis: test performance of ultrasonography for giant-cell arteritis. Ann Intern Med. 2005;142:359-69.

24. Arida A, Kyprianou M, Kanakis M, Sfikakis PP. The diagnostic value of ultrasonography-derived edema of the temporal artery wall in giant cell arteritis: a second meta-analysis. BMC Musculoskelet Disord. 2010;11:44.

25. Monti S, Floris A, Ponte CB, Schmidt WA, Diamantopoulos AP, Pereira C, et al. The proposed role of ultrasound in the management of giant cell arteritis in routine clinical practice. Rheumatology (Oxford). 2018;57:112-9.

26. Ješe R, Rotar Ž, Tomšič M, Hočevar A. The role of colour doppler ultrasonography of facial and occipital arteries in patients with giant cell arteritis: a prospective study. Eur J Radiol. 2017;95:9-12.

27. Blockmans D. Diagnosis and extension of giant cell arteritis. Contribution of imaging techniques. Presse Med. 2012;41(10):948-54.

28. Nesher G, Shemesh D, Mates M, Sonnenblick M, Abramowitz HB. The predictive value of the halo sign in color Doppler ultrasonography of the temporal arteries for diagnosing giant cell arteritis. $\mathrm{J}$ Rheumatol. 2002;29:1224-6.

29. Maldini C, Dépinay-Dhellemmes C, Tra TT, Chauveau M, Allanore Y, Gossec L, et al. Limited value oftemporal artery ultrasonography examinations for diagnosis of giant cell arteritis: analysis of 77 subjects. J Rheumatol. 2010;37:2326-30. 
Table 1. Clinical symptoms suspicious of giant cell arteritis.

Elevated ESR

Normocytic anaemia

Headache

Poor general conditions

Visual symptoms

Pain in girdles

Mandibular claudication

General syndrome

Stroke

Fever

Infarction
$49(85.9)$

37 (67.3)

35 (61.4)

26 (45.6)

$21(36.8)$

$21(36.8)$

14 (24.6)

$12(21.1)$

$6(10.5)$

$4(7)$

$2(3.5)$

Cases (\%). 
Table 2. Characteristics of patients diagnosed with GCA and patients with other non GCA diagnoses.

Diagnosis of GCA $(\mathrm{n}=21) \quad$ Other diagnosis $(\mathrm{n}=36) \quad P$

$\begin{array}{llll}\text { Sex, male/female }(\%) & 8 / 13(38 / 62) & 14 / 22(39 / 61) & .953 \\ \text { Age, mean } \pm \text { SD in years } & 77.38 \pm 8.58 & 73.86 \pm 8.47 & .119 \\ \text { AHT, cases (\%) } & 9(42.9) & 20(55.6) & .355 \\ \text { Antiaggregant treatment, cases (\%) } & 7(333) & 12(33.3) & 1.000 \\ \text { Anticoagulant treatment, cases (\%) } & 2(9.5) & 3(8.3) & .878 \\ \text { Charlson score, mean } \pm \text { SD } & .81 \pm 1.36 & 1.5 \pm 1.36 & .022^{*} \\ \text { Elevated alkaline phosphatase, cases (\%) } & 5(25) & 7(20) & .841 \\ \text { ESR, mean } \pm \text { SD mm/h } & 83.5 \pm 32.81 & 85.8 \pm 33.59 & .776 \\ \text { Normocytic anaemia, cases (\%) } & 14(70) & 23(65.7) & .745 \\ \text { Fever, cases (\%) } & 2(9.5) & 2(5.6) & .572 \\ \text { Poor general condition, cases }(\%) & 9(42.9) & 17(47.2) & .750 \\ \text { General syndrome, cases }(\%) & 8(38.1) & 4(11.1) & .016 * \\ \text { Mandibular claudication, cases }(\%) & 5(23.8) & 9(25.0) & .920 \\ \text { Headache, cases }(\%) & 13(61.9) & 22(61.1) & .953 \\ \text { Visual symptoms, cases }(\%) & 10(47.6) & 11(30.6) & .198 \\ \text { Joint and girdle pain, cases }(\%) & 8(38.1) & 13(36.1) & .881 \\ \text { Stroke, cases (\%) } & 2(9.5) & 4(11.1) & .851 \\ \text { Infarction, cases }(\%) & 1(4.8) & 1(2.8) & .695 \\ \text { Thickened artery } & 2(9.5) & 2(8.3) & .878 \\ \text { Painful nodules or pain on palpation } & 2(9.5) & 6(16.7) & .454 \\ \text { Absence of pulse } & 3(14.3) & 10(27.8) & .242\end{array}$

GCA: giant cell arteritis.

$* P<.05$. 
Table 3. Specialities that indicated temporal artery biopsy.

\begin{tabular}{lll}
\hline Internal medicine & $35(61.4)$ & $8(22.8)$ \\
Rheumatology & $18(31.6)$ & $10(55.5)$ \\
Neurology & $3(5.3)$ & $1(33.3)$ \\
Primary care & $1(1.7)$ & $0(0)$ \\
\end{tabular}

Cases (\%).

Table 4. Sensitivity and specificity of biopsy and ultrasound for GCA diagnosis.

\begin{tabular}{lll}
\hline & Sensitivity & Specificity \\
\hline Biopsy & $66.67(14 / 21)$ & $100(35 / 35)$ \\
Halo sign & $33.33(7 / 21)$ & $68.57(24 / 35)$ \\
Temporal stenosis & $14.29(3 / 21)$ & $94.29(33 / 35)$ \\
Arterial occlusion & $9.52(2 / 21)$ & $97.14(34 / 35)$ \\
Halo sign or stenosis of occlusion & $47.62(10 / 21)$ & $65.71(23 / 35)$ \\
\end{tabular}

$\%(\mathrm{n} / \mathrm{N})$. 